\title{
TRAJETÓRIAS CAMPONESAS: DO CENTRO-SUL À FRONTEIRA AGRÍCOLA DA AMAZÔNIA MERIDIONAL
}

\author{
Jacob Binsztok $^{\mathbf{i}}$ \\ Cecilia Werneck ${ }^{\text {ii }}$
}

\begin{abstract}
Resumo: o artigo analisa permanências e mudanças realizadas pelo campesinato proveniente do centro sul do país na fronteira agrícola da Amazônia Meridional, particularmente no centro de Rondônia. Assim, são analisadas as transformações ocasionadas pela redução da cafeicultura da variedade conilon e sua substituição pela pecuária leiteira, acompanhando um paradigma nacional ocorrido no Vale do Paraíba Fluminense, Zona da Mata de Minas Gerais e no norte do Paraná, e substancialmente agravadas pela política de erradicação de cafezais considerados improdutivos na década de 1970 no Espírito Santo e em outras áreas do centro sul do país. O trabalho resgata a contribuição de estudos precursores que abordam a questão da fronteira agrícola na Amazônia e paralelamente dos estudos clássicos que investigam a expansão do capitalismo contemporâneo no campo. 0 trabalho mostra que o campesinato se adaptou às inovações, contribuindo para as transformações socioespaciais da fronteira agrícola da Amazônia Meridional.
\end{abstract}

Palavras-chave: campesinato, Amazônia Meridional, centro de Rondônia, agronegócio e complexo de carne e grãos.

\section{COUNTRY PATHWAYS: FROM SOUTH CENTRAL TO AGRICULTURAL BORDER OF SOUTHERN AMAZON}

\begin{abstract}
The paper analyses the continuity and the changes accomplished by the peasantry coming from de Central-south of Brazil at the agricultural border of the Southern Amazon, particularly at the heart of Rondônia. Therefore, the analysis will focus on the transformations occurred by the reduction of the conilon variety coffee production and it's substitution by the dairy farming, following a national paradigm occurred in the Fluminense Paraiba river valley, the Zona da Mata of Minas Gerais and in the North of Paraná. Those transformations were substantially worsen by the eradication policy of unproductive coffee plantations during 1970 decade in the state of Espírito Santo and other regions in the Central-south of the country. This work brings the contributions of past studies that approached the issue of Amazon's agricultural border as well as classic studies that investigated the contemporary capitalism expansion in the
\end{abstract}

\footnotetext{
' Professor Titular do Programa de Pós-Graduação de Geografia da Universidade Federal Fluminense (PosGeoUfF). Bolsista de Produtividade Nível 2 CNPQ. Bolsista Cientista do Nosso Estado Email: jacobinsztok@gmail.com.

ii Bolsista do Programa de Iniciação Científica PIBIC da Universidade Federal Fluminense, Departamento de Geografia.
} 
countryside. The paper conclusion reflects the peasantry capacity to adapt to innovations and to contribute to the Southern Amazon agricultural border socio spatial transformations.

Keywords: peasantry, Southern Amazon, center of Rondônia, agribusiness and meat and grain complex.

\title{
CAMINOS POR PAÍS: DEL CENTRO SUR A LA FRONTERA AGRÍCOLA DE LA AMAZONÍA SUR
}

\begin{abstract}
Resumen: El documento analiza la continuidad y los cambios logrados por el campesinado proveniente del centro-sur de Brasil en la frontera agrícola del sur del Amazonas, particularmente en el corazón de Rondônia. Por lo tanto, el análisis se centrará en las transformaciones ocurridas por la reducción de la producción de café conilon y su sustitución por la producción lechera, siguiendo un paradigma nacional ocurrido en el valle del río Fluminense Paraíba, la Zona da Mata de Minas Gerais y en el norte de Paraná Esas transformaciones fueron empeoradas sustancialmente por la política de erradicación de los cafetales improductivos durante la década de 1970 en el estado de Espírito Santo y otras regiones en el centro-sur del país. Este trabajo aporta las contribuciones de estudios anteriores que abordaron el tema de la frontera agrícola de Amazon, así como estudios clásicos que investigaron la expansión del capitalismo contemporáneo en el campo. La conclusión del artículo refleja la capacidad del campesinado para adaptarse a las innovaciones y contribuir a las transformaciones socioespaciales de la frontera agrícola del sur del Amazonas.

Palabras clave: campesinado, sur de la Amazonía, centro de Rondônia, agronegocios y complejo de carne y granos.
\end{abstract}

\section{Introdução}

O povoamento e a colonização da fronteira agrícola na Amazônia Meridional, ao final da década de 1970, foram responsáveis por um processo de radicais transformações socioespaciais locais, como a introdução do cultivo do café da variedade conilon $^{1}$ no Centro de Rondônia, por intermédio de iniciativas individuais, construindo paulatinamente sua integração à economia regional, nacional e global. As origens do

\footnotetext{
${ }^{1}$ Variedade arbustiva adaptada a climas quentes e úmidos, com elevado teor de acidez e ingerido como blends (mistura) ou para fabricação de café solúvel. Diferente da variedade arábica, que conta com menos acidez, adaptado a climas com temperaturas menos elevadas, altitudes médias e ingerido de forma direta.
} 
referido processo podem ser percebidas quando se estrutura um movimento de Contra Reforma Agrária, promovido pelos Governos Militares, destinado a atender às demandas por terras de agricultores expropriados do centro-sul do país, principalmente dos estados do Paraná, Espírito Santo e Minas Gerais. Assim, observamos que o cultivo do café atinge a região não como resultado de políticas públicas destinadas ao desenvolvimento de atividades agrícolas, mas como alternativa de sobrevivência para os pequenos produtores, cujos cafezais foram considerados improdutivos pelo Instituto Brasileiro do Café (IBC) e pelo Grupo Executivo de Racionalização da Cafeicultura (GERCA), cumprindo determinações do Ministério da Indústria e Comércio do Governo Costa e Silva, inviabilizando sua permanência nos espaços rurais dos referidos estados.

É importante ressaltar que grande parte desses agricultores eram pequenos proprietários ou meeiros, que não tiveram outra alternativa a não ser abandonar as áreas onde sua reprodução encontrava-se vulnerável e sob risco de desaparecimento. Neste sentido, foram induzidos por intermédio da publicidade oficial e também por laços de compadrio e solidariedade, típicos do campesinato ${ }^{2}$, a se fixarem em lotes de 100 hectares nas áreas de mata da nova fronteira agrícola na Amazônia Meridional, principalmente no trecho rondoniense da rodovia 364, ligando Cuiabá a Porto Velho. A construção de estradas de integração entre a nascente fronteira agrícola aos mercados do Sudeste, insere-se na política de modernização conservadora, promovidas "de cima para baixo" pelas autoridades governamentais, responsáveis pelos grandes movimentos migratórios das décadas de 1970 e 1980 no país. Convém destacar os aspectos geopolíticos envolvidos na questão, pois tratava-se de ocupar vastas extensões da faixa de fronteira com a Bolívia, de ocupação rarefeita, com colonos do centro sul do país, em grande parte de origem europeia, invisibilizando as populações tradicionais e promovendo o "branqueamento" das comunidades locais por intermédio das migrações internas, privilegiando não mais as migrações nipônicas interrompidas em função da Segunda Grande Guerra Mundial. Neste particular, é relevante destacar as

\footnotetext{
${ }^{2}$ Sistema econômico e agrícola próprio, articulado ao capitalismo, fundamentado em grande parte no trabalho familiar e recorrendo eventualmente a trabalhadores temporários e parceiros.
} 
recomendações preconizadas por WAIBEL (1979) realçando a importância do campesinato de origem europeia para o sucesso dos empreendimentos de colonização na fronteira agrícola do país, antecipando em duas décadas as diretrizes autoritárias adotadas pelos Governos Militares privilegiando concepções eurocêntricas em detrimento das tradicionais populações ribeirinhas amazônicas. A preocupação de WAIBEL (1979) se justificaria na medida em que o referido geógrafo em função da destruição ocasionada pela Segunda Grande Guerra também estava interessado em encontrar espaços para a fixação de colonos alemães no país, não percebendo os esforços dos Estados Unidos em soerguer rapidamente as bases econômicas da Alemanha Ocidental.

Ao contrário do divulgado pelos ideólogos e planejadores governamentais da época, a Amazônia não poderia ser tratada como um "vazio demográfico", pois a região havia sido ocupada nas décadas de 1920/30 por antigos membros da Comissão Rondon, que por intermédio de títulos de arrendamento concedidos pelo Governo Federal, exploravam o látex de seringais nativos, conforme ressalta KEMPER (2002) e BINSZTOK (2008). Segundo os autores em estudos sobre o município de Cacoal, os seringalistas, por não possuírem títulos definitivos dessas propriedades, foram expropriados pelo Governo Militar, alguns terminando seus dias na periferia dos núcleos pioneiros dos Projetos de Colonização Integrada (PICs). Os seringalistas por não receberem indenizações, não tiveram oportunidade de monetizar o valor de suas terras, reduzidos à condição de proletários urbanos. Anteriormente à presença dos seringalistas, podemos mencionar a existência de populações indígenas, apontadas por MINDLIN (1985) e também pelas narrativas de participantes da Comissão Rondon, que encontraram aldeias Nambiquaras localizadas no trajeto percorrido pelos seus integrantes, e que ao longo do tempo sofreram significativas reduções nos seus contingentes populacionais. Assim, observamos que durante os trabalhos da Comissão Rondon foram estimados a presença de 5 mil Nambiquaras, reduzidos para 3 mil na época dos trabalhos da expedição de Lévi-Strauss, no final da década de 1930 , e totalizando cerca de 1500 por ocasião do Governo Fernando Henrique Cardoso, segundo informações da FUNAI, iniciando um 
processo de estabilização e lenta recuperação, atingindo na atualidade cerca de 1900 habitantes nas Terras Indígenas do Mato Grosso.

Os movimentos migratórios em direção a fronteira Amazônica foram analisados por MARTINS (1980), realçando os aspectos de recriação, ampliação e resistência do campesinato ao processo de desenvolvimento desigual e combinado do capitalismo contemporâneo no campo. Ao referido processo, foi acrescentada a grave questão ambiental, destacada por AB'SÁBER (2003), MILLIKAN (1999) e DIEGUES (1999), revelando que a depredação dos recursos naturais foi precedida por um sistema de alianças congregando inicialmente madeireiros e pecuaristas, e posteriormente segmentos do Complexo de Grãos, principalmente no cone sul do estado, mediante o pretexto de ocupação de terras anteriormente degradadas. Assim, observamos que durante a abertura das estradas vicinais do sistema de "linhões" construídos pelos Programas Integrados de Colonização (PICs), os referidos atores avançavam para o interior das áreas florestais, promovendo uma política de "terra arrasada", estimulada pelo próprio INCRA conforme menciona AB'SABER (2003), em extensas áreas no Centro de Rondônia, comprovadas pelas observações da figura 1. 
Figura 1 - Mapa de Desmatamento e Áreas Protegidas em Rondônia - 2007

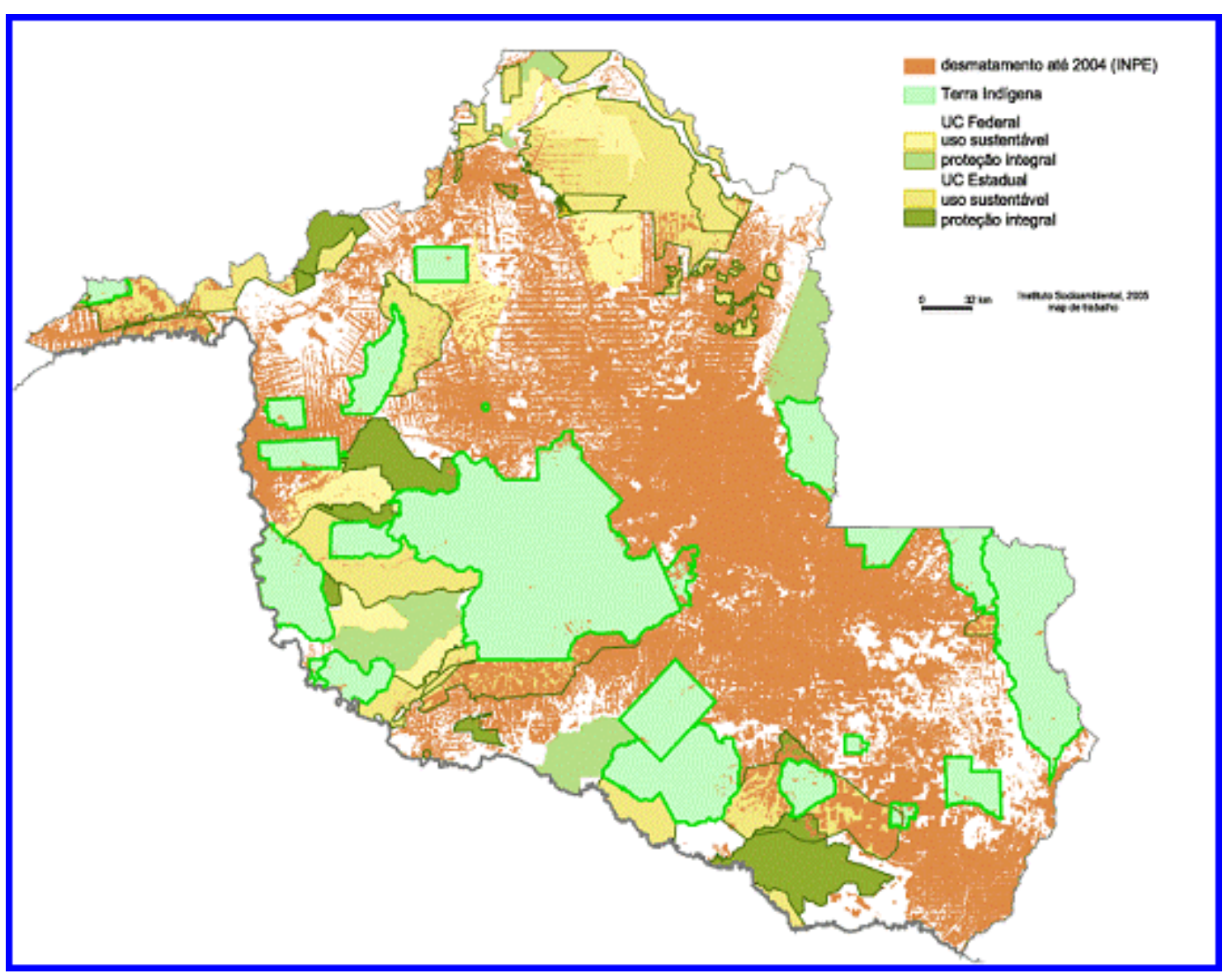

Fonte: IMAZON (2017)

Organização: Binsztok e Werneck (2018)

Atenuando as observações de AB'SÁBER (2003), BECKER (1982 e 2004) sugere que a malha municipal do atual estado de Rondônia, originária da implantação dos Programas de Colonização Integrada (PICS), pode ser considerada como uma floresta "urbanizada" na Amazônia. Assim, a pesquisadora destaca acertadamente a presença de pontos de modernização representados pela existência, embora incipientes, de equipamentos urbanos, como escolas, postos de saúde, sedes de instituições municipais, federais, estaduais e de organizações da sociedade civil. No entanto, os referidos pontos não conseguem atenuar os sérios problemas vivenciados pelas populações locais, que são periodicamente atingidas por queimadas, ocorridas durante a estação seca, colocando a região no denominado Arco do Desmatamento do IBAMA, considerado prioritário 
pelos programas governamentais e internacionais para as atividades de recuperação de áreas degradadas. As observações de BECKER (2004), procurando mitigar os efeitos ocasionados pelo denominado "Arco do Desmatamento" ou "Arco do Fogo" do IBAMA, permitem questionamentos, pois as "queimadas" em escala global estão sendo apontadas como responsáveis pelo agravamento do aquecimento do planeta e por problemas de saúde para a população local. Logo, "as queimadas" como expressão econômica de setores modernizantes, como fala BECKER (2004), permite reparos, pois tais procedimentos estão inseridos na tradicional lógica predatória de ocupação das áreas de fronteira do território brasileiro. Essas ocupações acarretam prejuízos para a preservação da biodiversidade amazônica e do Centro-Oeste, com implicações para todo o país na medida que nessas regiões encontram-se os mananciais das grandes bacias hidrográficas nacionais.

Acrescenta-se que o avanço desmedido do desmatamento foi acompanhado pela contaminação de rios e solos, atingidos pelo uso excessivo de agrotóxicos, conforme observações de BINSZTOK e MACEDO (2007). As cidades originárias desse processo cresceram sem estruturas urbanas adequadas, ocasionando o aumento de doenças decorrente da ausência de saneamento básico, e contribuindo para a mobilização e consequente formação de associações de agricultores reivindicando a mitigação desses problemas. Esses movimentos articularam a cooperação de entidades não governamentais e dos denominados setores progressistas da Igreja Católica, vinculados à Teologia da Libertação e a Conselho Episcopal Latino-Americano, priorizando o atendimento particularmente das comunidades rurais, mostrando-se também preocupadas com o avanço do desmatamento e depredação dos recursos naturais.

Assim, por intermédio de suas lideranças, decidiram investir no fortalecimento do campesinato como forma de preservar a biodiversidade e ainda o resgate dos saberes das populações tradicionais. Portanto, foram constatadas mudanças nas ações da Igreja Católica no campo, representadas pelo abandono das antigas práticas de catequese utilizadas pelas missões religiosas, e o advento de ações pautadas pela assistência social e ampliação da cidadania, substituindo em várias oportunidades a ausência e 
ineficiência do poder público nos níveis municipais, estaduais e federais. Torna-se relevante observar que estes movimentos provenientes muitas vezes de instituições internacionais, precisam ser melhor avaliados, pois as doações oferecidas a países da América Latina, particularmente às comunidades rurais, podem revelar a existência de políticas compensatórias, decorrentes do forte protecionismo adotado pelos países europeus em relação aos produtos agrícolas dos países periféricos.

A resistência camponesa apontada por MARTINS (1980) e ressaltada por OLIVEIRA (1986 e 1990) se manifestou sob diferentes formas, como pela mobilização dos movimentos sociais rurais na organização de assentamentos de Reforma Agrária, e ainda pela participação de camponeses na recuperação de áreas degradadas mediante práticas agroecológicas, agroflorestais, e incentivo ao comércio justo e à economia solidária, procedimentos preconizados por GRÜNINGER e URIARTE (2002), SAMPAIO e FLORES (2002). BINSZTOK e MACEDO (2007) ressaltam a importância das lideranças da Igreja Católica, particularmente sediadas na Diocese de Ji-Paraná, responsável pelo funcionamento do Projeto Padre Ezequiel e da ONG Terra Sem Males, procurando mitigar os efeitos da depredação dos recursos naturais locais com contribuições provenientes de instituições católicas alemãs, italianas e inglesas. Estas práticas procuraram mitigar os efeitos do desmatamento e o assoreamento dos cursos fluviais, reafirmando as observações de VELHO (1979) quando analisava a expansão da frente pioneira da rodovia Belém-Brasília, nos estados do Maranhão e do Pará, realçando a supremacia da "mata" sobre a "beira", ou seja, a importância da rodovia como principal eixo da modernização, em detrimento das tradicionais comunidades ribeirinhas, fato ocorrido também no centro de Rondônia.

Essas comunidades passam a ser preconceituosamente identificadas como obsoletas e pouco dinâmicas pelos novos colonos, não sendo considerados como detentores de tempos diferenciados, conforme assinala CHAYANOV (1982) e confirmada pelos trabalhos de CASTRO, MURRIETA e NEVES (2006). Segundo DOLLFUS (1972), as rodovias pioneiras servem para seccionar os espaços ocupados pelas comunidades tradicionais, que anteriormente apresentavam-se de forma espacialmente unificada, concentrada, 
ou seja, são rompidos os vínculos de solidariedade e permanência dessas populações. Para o autor, a rodovia pioneira também antecipa paulatinamente a tutela do urbano sobre o rural - dicotomia entre cidade e campo -, fato que ocorre nos municípios localizados ao longo da BR-364, no estado de Rondônia, situação também comprovada por COY (1995) quando observa o fechamento de escolas rurais em função da crise cafeeira e o consequente deslocamento dessas populações para os núcleos urbanos dos municípios.

É relevante ressaltar a participação de organizações como a COOCARAM (Cooperativa dos Produtores Rurais Organizados para Ajuda Mútua) e a Associação de Produtores Alternativos (APA), que investiram em inovações, fomentando o associativismo, o cultivo de produtos orgânicos, instituindo prêmios visando a melhoria da qualidade do café da variedade conilon e construindo articulações com instituições comunitárias internacionais.

\section{Fronteira Agrícola: precursores teóricos}

A elaboração de uma retrospectiva teórica realizada mediante a revisão de autores clássicos que investigaram as diferentes formações socioespaciais do desenvolvimento capitalista no campo, preconizaram inicialmente a terminalidade camponesa, fundamentada nos estudos de MARX (1974), KAUTSKY (1980) e LÊNIN (1982). No entanto, o ressurgimento das abordagens de CHAYANOV (1982), após um longo período de ostracismo motivado pela censura de seus trabalhos na antiga União Soviética, mostraram o campesinato dotado de um sistema econômico próprio e articulado ao capitalismo, não apontando para a terminalidade, contrariando os autores anteriormente mencionados. Posteriormente, as concepções terminais e aquelas influenciadas por CHAYANOV (1982) foram analisadas pelos pesquisadores que estudaram a ocupação da fronteira agrícola brasileira, particularmente no Centro-Oeste e na Amazônia, como VELHO (1979), analisando a expansão da fronteira agrícola na 
Amazônia Oriental, ao longo da rodovia Belém-Brasília, mostrando a influência dos movimentos migratórios na organização socioespacial local do campesinato.

O trabalho pioneiro de VALVERDE (1967), realizado em convênio do IBGE com a antiga Superintendência de Valorização Econômica da Amazônia (SPVEA), atual Superintendência de Desenvolvimento da Amazônia (SUDAM), destaca como a construção da rodovia Belém-Brasília provocou diferentes impactos socioespaciais no antigo norte do estado de Goiás, atualmente Tocantins, no oeste do Maranhão, centralizado pela cidade de Imperatriz, e no sul do Pará, onde a estrada assume características nitidamente amazônicas, com a sua consolidação proporcionada pelo asfaltamento promovido pelo Governo Militar com recursos do Banco Mundial. A rodovia aberta durante o Governo JK, foi abandonada durante Governo Jânio Quadros, que a denominou 'a estrada da onça', sendo sua prioridade revista pelos militares que acertadamente a consideraram estratégica e imprescindível para a Integração Nacional. Nesta linha, é importante lembrar a contribuição de GUERRA (1953) ao mencionar a importância de serem ocupadas as extensas áreas de fronteira localizadas na Amazônia e no Centro-Oeste, resgatando as diretrizes estabelecidas por Vargas no ano de 1937 em relação à posição estratégica da região e a constituição da denominada Faixa de Fronteira considerando o perímetro de 150 km como área de Segurança Nacional. Também é relevante salientar as pesquisas de WAIBEL (1979), recomendando que o processo de colonização do país fosse realizado pelos camponeses dotados de princípios éticos pautados pela valorização do trabalho e realçando uma perspectiva tipicamente eurocêntrica e desvinculada das tradicionais comunidades amazônicas e do Centro Oeste, bem como a necessidade de investimentos em insumos químicos para recuperação dos solos locais, considerados de baixa fertilidade para a agricultura comercial, descartando qualquer possibilidade de serem adotadas políticas públicas privilegiando populações indígenas, ribeirinhas e quilombolas.

Neste sentido, o autor prognosticou o advento do Complexo de Grãos, no sul de Rondônia, norte do Mato Grosso e sudoeste de Goiás, confirmados pelos trabalhos de FRANCO DA SILVA (2003), destacando a permanente necessidade de serem apropriadas 
inovações técnico científicas, que garantiriam a expansão do referido segmento, condição indispensável paro o desenvolvimento capitalista. É importante mencionar que enquanto na Belém-Brasília predominava o povoamento de migrantes provenientes do Nordeste e de Minas Gerais, na frente pioneira de Rondônia e do norte de Mato Grosso predominaram respectivamente os contingentes migratórios do norte do Paraná, Espírito Santo e de outros pontos do sul e sudeste do país, mostrando a existência de graves crises no relevante setor cafeeiro localizado no Sul e Sudeste do país.

Influenciado pelo sociólogo russo SHANIN (1983), MARTINS (1984) mostra os movimentos de recriação, ampliação e resistência do campesinato ao processo de desenvolvimento desigual e combinado do capitalismo no campo presentes na expansão da fronteira agrícola na Amazônia, onde significativo contingente de pequenos agricultores deslocados do Centro-Sul e Sudeste lutaram para obter acesso à terra de forma espontânea ou dirigida por intermédio dos Programas de Colonização Integrada (PICs). Nesta linha, MINC (1985) ressalta que a contribuição do povoamento realizado pelos PICs em Rondônia acrescida da atuação do INCRA na organização e distribuição dos lotes promoveram uma incipiente malha urbana fundamental para posterior fundação de novos municípios, fomentando um novo ordenamento territorial e político no estado, privilegiando os pioneiros do processo de colonização em detrimento das populações tradicionais, fato comprovado pelas observações de GIANASI (2012) no Centro de Rondônia.

Os trabalhos de campo realizados pela antropóloga MINDLIN (1985) mostraram a resistência do indigenato aos Projetos Integrados de Colonização (PICs) na região, movimentos que não foram considerados nos trabalhos de BECKER (1982) e também nos estudos anteriores de VALVERDE (1967) e WAIBEL (1979), na medida em que a questão indígena à época estava restrita às abordagens antropológicas, não sendo priorizada pela geografia do IBGE e tampouco assumida pelas disciplinas ministradas nos cursos universitários. Em outra vertente mais recente, dedicada aos estudos das relações de trabalho no campo, OLIVEIRA (1986 e 1990) destaca a luta pela posse da 
terra empreendida pelo campesinato na disputa com o latifúndio e por vezes envolvendo comunidades indígenas e com as burocráticas medidas tomadas pelos responsáveis pelas áreas de proteção ambiental. Ressaltando o referido processo de lutas, GONÇALVES (2001) adverte para a existência de várias Amazônias, ou seja, a região não deve ser tratada em uma perspectiva uniforme, e salienta a diferenciação socioespacial, recomendando a incorporação dos saberes das comunidades tradicionais locais e resgatando para a geografia dimensões que não eram consideradas nos trabalhos de VALVERDE (1967), WAIBEL (1979) e BECKER (1982) pelas razões já explicitadas.

\section{Transformações socioespaciais: Substituição do Cafeicultura pela Cadeia Produtiva ${ }^{3}$ de Leite}

O discurso oficial do Instituto Brasileiro do Café (IBC), na década de 1970 no Governo Costa e Silva, preconizava a eliminação dos cafezais no Centro Sul em virtude da baixa qualidade do produto e dificuldades na obtenção de preços no mercado interno e externo, entendendo que a queda dos preços do café era um reflexo do baixo rendimento das lavouras, e como solução foi proposta a eliminação das lavouras consideradas não produtivas. O discurso paralelamente contribuiu para o êxodo rural do Centro Sul para o povoamento da fronteira agrícola da Amazônia Meridional. Ao contrário da tendência nacional, tratava-se de um movimento representativo das populações rurais em direção aos espaços rurais da fronteira agrícola.

Contudo, a depredação contínua dos recursos naturais (BINSZTOK e MACEDO, 2007) e as sucessivas crises da lavoura cafeeira motivaram a formação de movimentos de recuperação de áreas degradadas, liderados em grande parte pelas Organizações Não Governamentais (ONGs) nacionais e estrangeiras, que não impediram a continuidade da exaustão dos solos e recursos hídricos, pois as intervenções mitigadoras de cunho

\footnotetext{
${ }^{3}$ Reunião de produtores - em grande parte camponeses - e as instalações de pequenos, médios e grandes beneficiadores do produto.
} 
ambientalistas eram de caráter pontual e disperso, apresentando fragilidades de gestão e captação de recursos.

Sob o signo da modernização conservadora ${ }^{4}$, a integração do território durante 0 Governo Militar se sustentou na narrativa da soberania nacional que buscava estabelecer uma política de ocupação dos "espaços vazios", tornando invisíveis as populações tradicionais, transformando-os em palco de atividades destinadas ao fortalecimento da economia nacional, e paralelamente desestimular iniciativas de âmbito internacional percebidas como ameaça permanente a unidade territorial do país. Ao mesmo tempo, a ocupação respondia a necessidade de adensar o povoamento das fronteiras do país, tanto na narrativa de uma proposta de integração, enquanto espaços potenciais de expansão do capital nacional e global, quanto pela preocupação em fortalecer seu monitoramento controlando as ameaças de teor político, que circulavam em países vizinhos.

Assim, a nova ordem territorial instalada e a formação de esferas de poder local em Rondônia, contaram com a presença institucional do INCRA, responsável pela distribuição de lotes para migrantes nas vilas construídas pelos programas de colonização, que ocupavam os linhões - estradas vicinais -, partindo da BR-364, em direção a mata. Ocorreu também um movimento de colonização espontânea, sem mediações públicas, através da recriação de sistemas de produção originários da sua experiência empírica, como explica KEMPER (2002), indo além da cafeicultura.

Na cafeicultura no Centro de Rondônia predomina a variedade conilon, considerada indispensável para a fabricação de blends ${ }^{5}$ e solúveis, melhor adaptada ao clima tropical com duas estações bem diferenciadas e aos solos de menor fertilidade do que o exigido pela variedade arábica. A comercialização sofre obstáculos devido ao grande número de defeitos, cerca de 400 a 500, não se enquadrando nos padrões mínimos da classificação

\footnotetext{
4 Modernização Conservadora (ou a chamada Via Prussiana para o desenvolvimento econômico) corresponde a um movimento de modernização promovida pelo capitalismo no campo ou na cidade, sem, contudo, alterar as estruturas vigentes, como, por exemplo, sem modificar a concentração de terras controladas pelos grandes proprietários.

${ }^{5}$ Mistura de até $20 \%$ do conilon na manipulação para o consumo da variedade arábica.
} 
oficial utilizada pela cadeia de intermediários (que monopolizam a comercialização do café), iniciada pelo tipo 8, que admite até 360 defeitos, e que segue até o tipo 1, com poucos defeitos. Contudo, a produção conquista significativa importância a nível local, regional, estadual e nacional, ocupando o segundo lugar na produção de café da variedade "robusta" no país, e a primeira posição do produto na Amazônia, conforme demonstram as pesquisas realizadas por VENEZIANO (2005), que foi um dos responsáveis pela colocação do café desta variedade na pauta das prioridades da Estação Experimental da EMBRAPA de Ouro Preto d'Oeste.

A construção da imagem de um eldorado brasileiro marcado pela infinitude dos recursos naturais, favoreceu a sua depredação e o advento de movimentos migratórios interregionais, conforme menciona BECKER (1982 e 2004), com agricultores aproveitando-se de estradas vicinais e do baixo preço da terra para adquirirem propriedades nas novas áreas de fronteira agrícola, como observamos no município de Buritis, localizado nas proximidades dos estados do Mato Grosso, Amazonas e Acre. Esses movimentos especulativos revelam também a presença de um patrimonialismo dos "de baixo", que acompanha a trajetória dos pequenos produtores no avanço da depredação dos recursos naturais, ocasionando marcas da 'terra arrasada' e colocando em destaque uma aliança entre madeireiros e pequenos produtores. Também, encontramos nas áreas periféricas dos centros urbanos movimentos revelando a aquisição de pequenos sítios por proprietários urbanos, facilitando o surgimento de novas áreas de produção, inclusive para expansão do cultivo de legumes, hortaliças e frutas que abastecem os mercados locais, e ainda áreas de lazer e entretenimento. $\mathrm{O}$ fato, além de comprovar o não fechamento da fronteira, preconizado por GRAZIANO DA SILVA (1982), também pode ser considerado um dos indicadores da não terminalidade camponesa, e paradoxalmente pode ser apontado como responsável pelo surgimento de novos focos de desmatamento, que poderão ocorrer em função de uma possível retomada da ocupação e do povoamento da BR-319 - Porto Velho - Manaus -, conforme salienta FEARNSIDE (2009). 
O esgotamento dos solos, poluição de rios pelo excessivo uso de agrotóxicos, juntamente com a dificuldade de comercialização do café, por conta dos intermediários que estabelecem preços fixos para o transporte, além do baixo preço pago ao produtor, como resposta a concorrência da produção do Vietnã, que conta com subsídios provenientes de reparação de guerra, são fatos que contribuem para formação de novos espaços agrícolas para produção de leite no Centro de Rondônia. A exaustão dos recursos naturais eliminou um expressivo contingente de cafeicultores, porém um outro contingente do campesinato acabou envolvido no agronegócio leiteiro, constituindo-se em um importante contraponto ao indiscriminado avanço do Complexo de Carne e Grãos, centralizado em Vilhena, expandindo-se pelo denominado Cone Sul, em direção à fronteira com a Bolívia. Contudo, as iniciativas para a expansão da soja no Centro de Rondônia, não foram bem-sucedidas, pois as “... podemos afirmar que, em linhas gerais, a Amazônia Meridional vivenciou as condições geomorfológicas não favoreceram a mecanização para a produção em grande escala de grãos.

Segundo o trabalho de SMERALDI (2008), as dificuldades foram menores em relação aos empreendimentos da pecuária de corte, que ocupa a 7ạ posição no ranking nacional, com um rebanho estimado em 13 milhões de cabeças, adaptadas com facilidade às condições locais. É relevante mostrar que Rondônia, segundo dados do IBGE/2017, possui uma população de 1,8 milhões de habitantes, constatando-se uma proporção de 6 animais para cada habitante, comprovando a depredação dos recursos naturais exigida pela expansão da pecuária extensiva de corte ou leiteira, evidenciando desequilíbrio na ocupação do espaço agrário do estado. A formação dos pastos foi precedida de desmatamentos, em grande parte ilegais, e o rebanho foi colocado em 
sistemas ecológicos frágeis, acelerando processos erosivos e de assoreamentos. Para o autor, grande parte da expansão do rebanho bovino nacional é proveniente da abertura de novas frentes de ocupação nas áreas da fronteira agrícola, consolidada ou não, da Amazônia e do Centro-Oeste.

Com relação à produção leiteira, técnicos da EMBRAPA consideram-na baixa, estimando uma média de 3,75 litros/dia, embora o estado possua a oitava bacia leiteira do país, a mais expressiva da região Norte, com cerca de 50 laticínios de pequeno e 2 de grande porte. A instituição pretende aumentar a produção de leite do rebanho nacional, prioridade considerada vital para os interesses do país. Além de atender ao mercado interno, o objetivo da EMBRAPA/MG seria colocar a produção brasileira no mercado internacional, à semelhança do ocorrido com a Nova Zelândia, que apesar da distância, tornou-se o maior responsável pelo abastecimento de leite da União Europeia.

As dificuldades vivenciadas pelo campesinato podem ser verificadas quando examinamos as transformações socioespaciais decorrentes da produção de leite, que inviabilizam determinadas relações de trabalho tipicamente camponesas, tais como a ajuda mútua, solidariedade, policultura e mutirão, em detrimento da especialização, redução da força de trabalho no campo e fortalecimento do monopólio dos canais de comercialização. Assim, a análise dos dados contidas nos gráficos 1 e 2, comprovam os movimentos de mudança envolvendo os respectivos produtos nos municípios do estado de Rondônia. 


\section{Gráfico 1}

Rondônia: Evolução da Produção Cafeeira (2000-2015) - ton

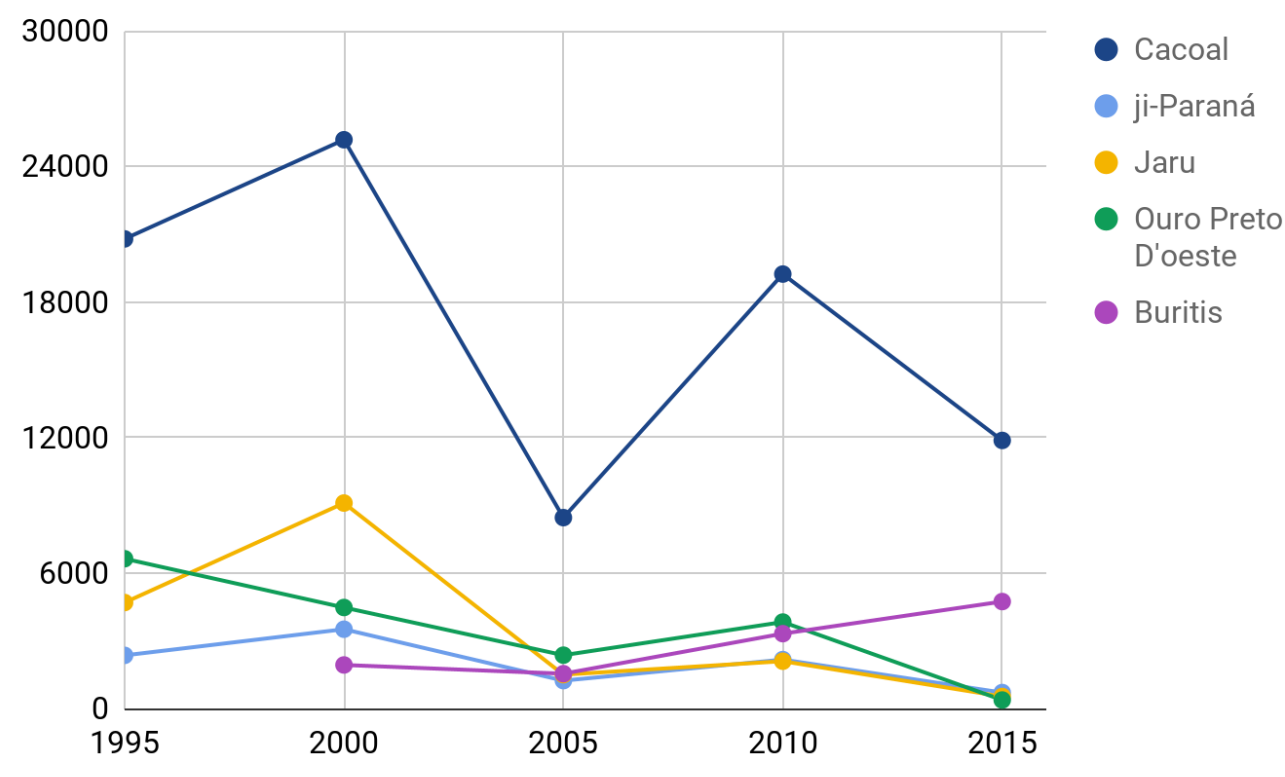

Fonte: IBGE / SIDRA, 2018.

Elaboração: Jacob Binsztok e Cecilia Werneck, 2018. 


\section{Gráfico 2}

Rondônia: Evolução da Produção Leiteira (2000-2015)- Mil L

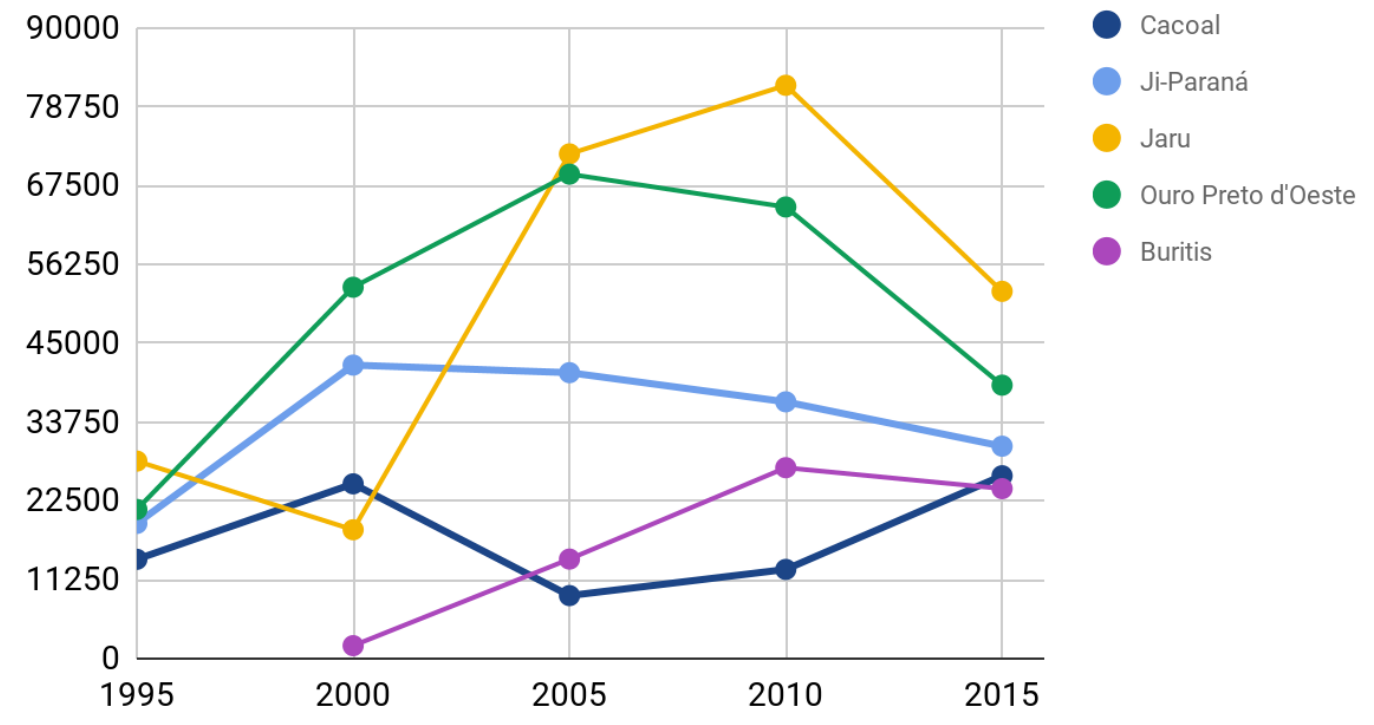

Fonte: IBGE / SIDRA, 2018.

Elaboração: Jacob Binsztok e Cecilia Werneck, 2018

A leitura dos gráficos 1 e 2 revela as oscilações da produção cafeeira e leiteira, ocorridas no período 1995-2015, destacando-se a significativa redução, porém a não eliminação da cafeicultura, e os tradicionais movimentos oscilatórios que caracterizam a produção de leite, onde percebemos ciclos de ascensão e queda entre os respectivos produtos. Contudo, percebe-se a nítida redução da cafeicultura nos municípios de Cacoal, JiParaná, Jaru e Ouro Preto do Oeste e o aumento da produção em Buritis, representado pela expansão de novas áreas da fronteira agrícola de Rondônia.

Paralelamente, observa-se o aumento da produção leiteira, centralizada nos municípios de Jaru, Ouro Preto do Oeste e Ji-Paraná, onde se concentram as unidades produtivas e beneficiadoras do produto.

A análise dos gráficos comprova a substituição da cafeicultura pela produção de leite no Centro de Rondônia, seguindo um paradigma clássico do espaço agrário brasileiro já ocorrido na Zona da Mata mineira e no Vale do Paraíba fluminense. Nestas áreas, a depredação dos recursos naturais e periódicas crises impactando o preço do café 
também contribuíram para a transformação dessas propriedades em áreas destinadas à formação de pastagens e à implantação de rebanhos leiteiros, beneficiando-se da proximidade de centros consumidores, na época consideradas posições geográficas estratégicas para contribuir para o desenvolvimento agrícola do Sudeste brasileiro.

\section{Considerações Finais}

Os estudos mostraram que a permanência do campesinato nas áreas rurais da fronteira agrícola da Amazônia Meridional não se caracterizou por um roteiro determinista, ao contrário, o segmento foi capaz de acompanhar as transformações socioespaciais, conforme aponta SOJA (1993), quando analisa os movimentos ocasionados pela reestruturação produtiva contemporânea, adaptando-se a uma série de procedimentos que não estavam previstos em suas práticas tradicionais. Assim, verificamos que o advento da cafeicultura, da produção de leite e de verduras e legumes destinadas ao consumo dos centros locais, regionais e nacionais, podem ser consideradas iniciativas autônomas do campesinato oriundo do Centro-Sul do país, não estando vinculadas às políticas públicas emanadas do INCRA.

A análise das informações contidas nas tabelas e mapas, mostraram de forma substituição gradual da cafeicultura do tipo conilon em certas áreas do centro de Rondônia, provocada por um longo ciclo de redução de preços e paralelamente pela depredação de recursos naturais, pela pecuária leiteira, seguindo um paradigma nacional semelhante ao ocorrido no Vale do Paraíba Fluminense, Zona da Mata Mineira, no Norte do Paraná e do Espírito Santo. O campesinato contribuiu para a construção da mais relevante bacia leiteira da Amazônia, transformando-a em um laboratório de experiências sobre a produção de leite em uma região geográfica estratégica que simultaneamente funciona como portal de entrada para as vastas extensões do trópico úmido brasileiro e sulamericano, na medida que também atinge regiões da Bolívia e do Peru, e ainda articulada ao centro sul do país pelos eixos rodoviários que percorrem os 
mercados de Mato Grosso, Goiás, Minas Gerais e São Paulo. Neste sentido, podemos afirmar que, em linhas gerais, a Amazônia Meridional vivenciou as grandes transformações socioespaciais ocorridas a nível nacional, inserindo-se na área de influência geoeconômica periférica ao estado de São Paulo, fato comprovado pela expansão do agronegócio no estado que se comportou como um prolongamento político paulista durante as eleições presidenciais de 2018.

O impacto da crise global de 2008 pode ser percebida na região quando observamos o comportamento dos imigrantes retornados da Europa, particularmente da Espanha, Itália, Alemanha e Holanda, aos municípios do Centro de Rondônia, em busca de oportunidade de trabalho. O retorno funcionou como fomento à expansão da produção leiteira, pois os retornados, em função do agravamento de crise na União Europeia, se agregaram em torno de parentes envolvidos na cadeia produtiva e paulatinamente se inseriram na referida atividade. Este comportamento revela articulação entre local e global, mostrando que o local não foi eliminado pela expansão do capitalismo contemporâneo, contrariando argumentos de autores clássicos, que acreditavam na ampla superação das cadeias produtivas globais sobre as comunidades locais, impedindo-as de participarem devido a um processo de seletividade espacial.

Cabe destacar a atuação dos agricultores vinculados aos sistemas agroecológicos e agroflorestais, que apesar das dificuldades enfrentadas para o escoamento da produção e volatilidade dos recursos ofertados por instituições nacionais e internacionais, continuam se mantendo, embora tenha tido problemas na sua inserção no comércio justo e a economia solidária, pois estas cadeias produtivas exigem o cumprimento certificações que em grande parte não se apresentam acessíveis aos produtores locais. Embora a produção leiteira não tenha apresentado problemas graves de expansão, as relações de trabalho continuam destacando a presença do campesinato, na medida em que o trabalho familiar e relações não capitalistas fundamentadas no compadrio e nas práticas de solidariedade, ainda são encontradas nas comunidades locais. No entanto, é possível que as ações de ajuda mútua como o "mutirão", sofram dificuldades de permanência como categoria importante nas relações de trabalho do campesinato 
particularmente dedicado a produção de leite, na medida em que essa atividade, devido ao seu grau de especialização e reduzida absorção de mão de obra, não oferece oportunidades para mobilização voluntária da comunidade, ao contrário da cafeicultura, que absorve um razoável contingente de trabalhadores, principalmente durante a colheita. Contudo, sobrevive ainda a mobilização das populações locais para atividades lúdicas, como campeonato de futebol e festas religiosas, que não desapareceram por completo nas relações sociais do campesinato da Amazônia Meridional.

\section{Referências bibliográficas}

AB'SÁBER, A. N. Os Domínios de Natureza no Brasil: Potencialidades Paisagísticas. São Paulo. Ateliê Editorial, 2003.

BECKER, B. K. Geopolítica da Amazônia. Rio de Janeiro: Zahar Editores, 1982. . Amazônia. Série Princípios. São Paulo: Editora Ática, 1991. Amazônia. Geopolítica na Virada do III Milênio. Rio de Janeiro: Editora Garamond, 2004.

BINSZTOK, J. Expansão do processo de acumulação de capital flexível no campo. In: Ordenamento Territorial e Ambiental. BARBOSA, J. L \& LIMONAD, E. (orgs.). Editora UFF. Niterói, 2012.

Projetos Integrados de Colonização: Paradigma da Contra-Reforma Agrária Promovido pelo Regime Militar nos anos 1970 na Amazônia. Anais Simpósio Internacional de Geografia Agrária. SINGA, Novembro, UFF, 2009.

- Transformações sócio-espaciais da agricultura familiar na Amazônia.

Scripta Nova: revista electrónica de geografía y ciências sociales, 2008: Vol.: 12 Diez años de cambios en el mundo, en la Geografía y en las Ciencias Sociales, 1999-2008.

As Diferenças sócio-espaciais dos produtos familiares dedicados ao cultivo do Café na Amazônia. Scripta Nova Revista Electronica de Geografia y Ciencias sociales. Universidad de Barcelona. ISSN: 1138-9788. Depósito Legal: B. 21.741-98. Vol. X, núm. 218, 1 de agosto de 2006.

A Inserção da Amazônia na Reestruturação Produtiva do Espaço Agrário Brasileiro. Anais do XIV Encontro Nacional de Geógrafos - Associação dos Geógrafos Brasileiros (AGB). Universidade Federal do Acre - Rio Branco, 2006a. 
BINSZTOK, J., MACEDO, G. R. Associações dos Agricultores Familiares, Cafeicultura Orgânica e Comércio Justo na Amazônia: Dilemas e Perspectivas. Revista Nera, ano 10, n¹0, 2007.

BINSZTOK, J., CARNEIRO, M. Integração Nacional, Desenvolvimento Capitalista e Projetos Modernizantes na Amazônia: retrospectiva e perspectiva de despojos da Mineração Rio do Norte - PA. Revista Nera, Presidente Prudente, Ano 18, №28, Edição Especial, p. 92-105, 2015.

BRASIL. Ministério do Desenvolvimento Agrário. Referências para o desenvolvimento sustentável. Brasília: NEAD, 2003

- Ministério do Desenvolvimento Agrário - MDA. Programa Nacional de Desenvolvimento Sustentável de Territórios Rurais: referência para o apoio ao desenvolvimento territorial. MDA/SDT, Brasília, 2004, mimeog.

CASTRO, F. Economia Familiar Cabocla na Várzea do Médio-Baixo Amazonas. In. Sociedades Caboclas Amazônicas: modernidade e invisibilidade. Org. ADAMS, C., MURRIETA, R., NEVES, W. São Paulo: Annablume Editora, FAPESP, Ano 2006. Segunda reimpressão, 2008. p. 173-194.

CHAYANOV, A V. O Desenvolvimento do Capitalismo na Rússia. Capítulos I a IV. SP: Abril Cultural, 1982.

COY, M. Cidades Pioneiras e Desenvolvimento Sustentável na Amazônia Brasileira. Transformação Sócio-Econômica e Desafios para o Planejamento nas Frentes Pioneiras. Florianópolis-SC: Geosul n.o 19/20 - Ano X, 1995.

. Frentes Pioneiras perante a Globalização. Dinâmica Interna e reorganização do Espaço Social na Amazônia Brasileira. Florianópolis-SC: Geosul no 25 - Ano XIII, 1998.

DIEGUES, A. C. (Org.) Desmatamento e modos de vida na Amazônia. São Paulo: NUPAUB/USP, 1999.

DOLLFUS, O. O espaço geográfico. São Paulo: Difel, 1972.

EMPRAPA - Centro Nacional de Pesquisa de Gado de Leite (Coronel Pacheco- MG). A importância do produto leite e as bacias leiteiras do Brasil. Coronel Pacheco, 1977.

FEARNSIDE, P. M. A Ocupação Humana de Rondônia: Impactos, Limites e Planejamento. Assessoria Editorial e Divulgação Científica, Brasília, 1989.

FEARNSIDE, P.M \& GRAÇA, M. BR 319 - A rodovia Manaus-Porto Velho e o impacto potencial de conectar o Arco do Desmatamento à Amazônia Central. Cadernos do NAEA, vol. 12, n¹, p. 19-50, 2009. 
GIANASI, L. M. Novas Territorialidades no Centro de Rondônia. Agricultura e as Questões Econômicas, Sociais e Ambientais (1970 - 2011). Tese de Doutorado. UFMG. 2012.

GONÇALVES, C. W. P. Amazônia, Amazônias. São Paulo: Contexto, 2001.

INCRA. Instituto Nacional de Colonização e Reforma Agrária. Colonização em dados, Brasília, 1983.

Relatório. Os problemas da colonização em Rondônia. 1984. Disponível em: <www.albertolinscaldas.unir.br/eliaquimdecunha.vol16.html>

INSTITUTO BRASILEIRO DE GEOGRAFIA E ESTATÍSTICA. Pesquisa de Pecuária Municipal. Disponível em: <http://www.sidra.ibge.gov.br> Acesso em: 24/05/2013.

INSTITUTO BRASILEIRO DE GEOGRAFIA E ESTATÍ́STICA.

KAUTSKY, K. A Questão Agrária. São Paulo: Proposta Editorial, 1980.

KEMPER, Lourdes. Cacoal: Sua História Sua Gente. Goiânia-Goiás: Editora Grafopel, 2002.

LÊNIN, V. O desenvolvimento do capitalismo na Rússia: processo de formação do mercado interno pela grande indústria. São Paulo: Abril Cultural, 1982.

MARTINS, J. S. Expropriação \& violência: a questão política no campo. São Paulo: Hucitec,1980.

MARTINS, J. S. A Militarização da Questão Agrária no Brasil. Petrópolis: Vozes, 1984.

MARX, K. O Capital. Livro III. vol.5 e 6. Rio de Janeiro: Civilização Brasileira, 1974.

MILIKAN, B. A experiência contemporânea da fronteira agrícola e o desmatamento em Rondônia. In: DIEGUES, A. C. (org.). Desmatamento e Modos de Vida na Amazônia. São Paulo: NUPAUB/USP, 1999.

MINDLIN, B. J. Nós PAITER - Os suruí de Rondônia. Petrópolis: Vozes, 1985.

MINC, C. A Reconquista da Terra. RJ: Zahar editores, 1985.

OLIVEIRA, A. U. Modo Capitalista de Produção e Agricultura. SP: Editora Ática, 1986.

Papirus, 1990.

Amazônia, Monopólio, Expropriação e Conflito. Campinas - São Paulo: . Agricultura camponesa no Brasil. São Paulo: Editora Contexto, 1997.

OLIVEIRA, O. A. de. História, Desenvolvimento e Colonização do estado de Rondônia. Porto Velho: Dinâmica, 2001. 
OLIVEIRA, J. L. Rondônia. Geopolítica e Estrutura Fundiária. Porto Velho: Grafiel, 2010.

SAMPAIO, F.; FLORES, M. Comércio ético e solidário e agricultura familiar brasileira. São Paulo: Fundação Friedrich Ebert/ILDES, 2002.

SANTOS, M. Técnica, Espaço, Tempo - Globalização e Meio Técnico- Científico Informacional. São Paulo: Hucitec, 1994.

M. O Retorno do Território. In: Santos, M. et al. Território, Globalização e Fragmentação. São Paulo: Hucitec, 1994, p 15-20.

M. A Natureza do Espaço: Técnica e Tempo, Razão e Emoção. São Paulo: Hucitec, 1996.

SHANIN, T. La Clase incómoda : Sociología política del campesinado en una sociedad en desarrollo : (Rusia 1910-1925)

SILVA, Carlos Alberto Franco da. Grupo André Maggi: corporação e rede em áreas de fronteira, Cuiabá: Entrelinhas, 2003.

SOJA, E. W. Geografias pós-modernas: a reafirmação do espaço na teoria social crítica. Rio de Janeiro: Jorge Zahar, 1993.

SMERALDI, R. e MAY, P. H. O Reino do Gado: Uma nova fase na pecuarização da Amazônia. Amigos da Terra - Amazônia Brasileira. São Paulo, 2008.

THÉRY, H. Rondônia: Mutações de um Território Federal na Amazônia Brasileira. 1ạ ed. Curitiba: SK Ed. 2012.

VALVERDE, O. DIAS, C. V. A Rodovia Belém-Brasília, Editora IBGE, 1967.

VELHO, O. G. Capitalismo Autoritário e Campesinato. (Um estudo comparativo da fronteira em movimento). São Paulo: DIFEL, 1979.

VENEZIANO W. \& OlIVEIRA S. J. M. Aspectos econômicos do Café em Rondônia, 2005. Disponível em <http://www.coffeebreak.com.br>

WAIBEL, L. Capítulos de Geografia Tropical e do Brasil. Rio de Janeiro: IBGE, 1979.

https://sidra.ibge.gov.br/tabela/1613

https://sidra.ibge.gov.br/tabela/74

https://temas.folha.uol.com.br/projeto-amazonia/br-319/estrada-que-liga-manaus-aresto-do-pais-ameaca-abrir-uma-alemanha-na-mata.shtml

Data de Submissão: 27/11/2019

Binsztok e Werneck, Trajetórias Camponesas: do Centro-Sul à Fronteira Agrícola da Amazônia Meridional DOI: https://doi.org/10.51308/continentes.v1i18.247 
Revista Continentes (UFRRJ), ano 10, n. 18, 2021

Data do Aceite: 05/03/2021 